\title{
La participación directa de los usuarios en la gestión de los regadíos de gobierno municipal y su interdependencia con la oligarquía urbana. La Plana de Castelló (ss. XVI-XVIII)
}

\author{
Cristian Pardo Nacher \\ Universitat de Vaència \\ cpardonacher@gmail.com
}

\begin{abstract}
Resumen. Siguiendo la tendencia actual de reducir las diferencias entre los dos modelos de gestión de regadíos valencianos (autónomo y municipal), el presente trabajo se centrará en el caso de la Plana de Castelló para tratar de mostrar cómo las oligarquías urbanas no asumieron todo el protagonismo en la gestión de estas huertas desde sus cargos municipales. De esta manera, nuestro principal objetivo será el de aportar vestigios documentales que nos permitan aproximarnos al importante papel jugado por el conjunto de los usuarios en dicha gestión durante la Época Moderna, así como la exposición de los diferentes cauces de participación y su relación con las autoridades municipales. Uno de estos cauces, fue el de la asamblea de regantes, un elemento bastante desconocido para los regadíos de gestión municipal, pero crucial para resolver ciertos aspectos de importancia. Por tal motivo, analizaremos cuáles fueron las necesidades que llevaron a sus convocatorias, que similitudes y diferencias formales tenían con las de la Huerta de Valencia, y finalmente, cuál fue su heterogénea composición social y la interacción existente entre la oligarquía urbana y el resto de los usuarios.
\end{abstract}

Palabras Clave: recursos de aprovechamiento común, Plana de Castelló, huertas de gestión municipal, instituciones de riego y asambleas de regantes.

\begin{abstract}
Nowadays, the differences between two Valencian irrigation management models (autonomous and municipal), has been reduced to little formal aspects. This paper will focus on the Castelló de la Plana case to try to show how local oligarchy did not assume the leading role in these orchards. Our main target will be to approach us to the important role played by the users in the communal management during the modern age and to expose their different participation channels. One of these channels was the assemblies of irrigators, an unknown concept in the municipal management model, but crucial to resolve collective action problems. Therefore, we will analyze the needs that led to their calls, the formal similarities and differences with autonomous model, and finally, the heterogeneous social composition and their interaction with the authorities.
\end{abstract}

Keywords: common-pool resources, Plana de Castelló, municipal administration, irrigation institutions and assemblies of irrigators.

\section{Introducción}

En el año 1970, Thomas Glick, propuso en su importantísima obra Irrigation and Society... la existencia de una dualidad de modelos de gestión en los regadíos históricos valencianos. Por una parte, el "modelo autónomo", donde -siguiendo el excepcional caso de la Huerta de Valencia- el gobierno de las aguas correspondía a comunidades de regantes autónomas, y por otra, el "modelo municipal" -más generalizado-, cuya gestión recaía sobre los Consells. Este modelo dual, parecía tener sus principales diferencias en la estratificación y la distribución social existente en cada huerta (Glick, 1988: XIII) de tal modo que en la 
gestión de cada modelo predominaba supuestamente un grupo social diferente ${ }^{1}$. Mientras que en las huertas de gestión municipal se hablaba en términos de poder oligárquico, para el caso de Valencia se llegó a pensar que la gestión autónoma de sus regantes era un idilio anacrónicamente democrático con la celebración de unas Juntas Generales donde se tomaban las decisiones entre todos ${ }^{2}$.

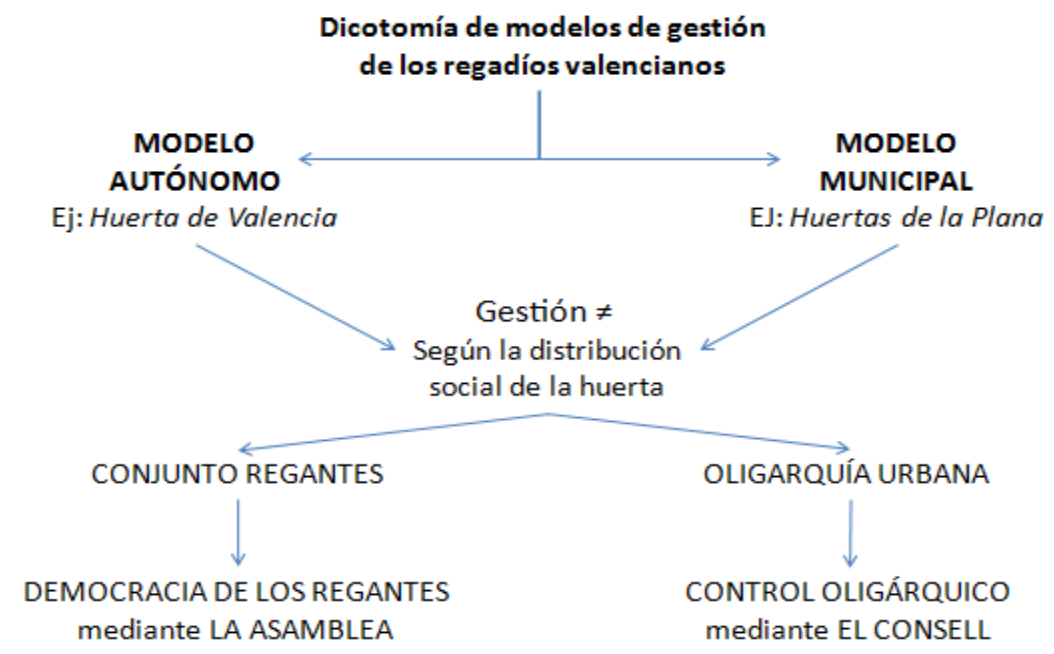

Fig. 1. Esquema tradicional sobre la dualidad de modelos de gestión de los regadíos valencianos. Elaboración propia.

Esta visión tan optimista en torno a la "democracia de los regantes" ha sido puesta en duda por diversos especialistas como Mateu y Romero (1991), Peris (1997 y 2014) y Garrido (2011 y 2012b). Los tres primeros al situar el origen del mito en el Ochocientos y explicar cómo éste fue usado por la oligarquía decimonónica en los momentos en que se sentía amenazada por las transformaciones de la Revolución Burguesa, y el último al observar que en el siglo XIX, no todos los que tenían voz en las juntas generales eran verdaderos regantes, puesto que alrededor del $90 \%$ de la superficie de la Huerta era explotada por arrendatarios sin acceso a ellas. Aunque, dicho autor señala que a quienes sí tenían voz y voto les podía interesar la participación de los arrendatarios, puesto que resulta poco realista suponer, pues, que fueran los propietarios absentistas quienes decidiesen el día del riego, o que un sistema tan complejo pudiese funcionar sin que la inmensa mayoría de regantes participase en el consenso.

Desde la formulación de la dicotomía de modelos de gestión, diversos autores (Furió, 1982 y Peris, 1992, 2003 y 2014) -entre los que podemos incluir al propio Glick ${ }^{3}$ - han ido recortando las distancias existentes entre ambos. Hoy en día las diferencias han quedado reducidas a aspectos puramente formales. Por este motivo, siguiendo con la tendencia

1. La diferencia entre ambos modelos también se ha tratado de explicar de la siguiente manera: el modelo autónomo suele darse en aquellas grandes ciudades de origen islámico donde existe una diversidad de sistemas hidráulicos. El modelo municipal, por su parte, allí donde haya una coincidencia entre el término municipal y un único sistema de riego (Guinot, 2007: 109).

2. En Garrido (2012b) se recogen los comentarios de algunos ingenieros y geógrafos extranjeros (Roberts, Markham, Moncrieff, Higgin, Roth, Nadault de Buffon, Aymard, Brunhes i Jaubert de Passa) que, debido a la visión ofrecida por los "acaudalados e instruidos terratenientes" durante el siglo XIX, ayudaron a la generalización de diferentes errores sobre los regadíos históricos valencianos.

3. Glick, T. (1988: XIII y 44) "La administración de las acequias municipales, tales como la Cèquia Maior de Castellón, difería poco de la de las acequias de la huerta de Valencia". 
actual de efectuar un acercamiento entre los dos modelos, creemos que de la misma manera que Calatayud y Garrido (2012: 96-97) han hablado de las limitaciones de la autonomía de los regantes en el Júcar decimonónico y Peris (2014) ha destacado el importante papel jugado por los municipios y la corona ${ }^{4}$ en la Huerta de Valencia, es también conveniente hacer lo propio desde el otro lado, y elaborar una aproximación sobre la participación de los usuarios en el modelo municipal, donde tradicionalmente se ha hablado en clave de poder oligárquico. Esta aproximación es cuanto menos inquietante ya que a partir de ella surge una pregunta clave. Si es cierto que los dos modelos solo gozaban de diferencias formales, ¿cuál fue la justa medida en la que las oligarquías y el resto de usuarios participaron en la gestión de las huertas gobernadas por los Consells?

Creemos que la respuesta tiene cierta relevancia, puesto que si planteamos estas instituciones como unos espacios con usuarios de diferente condición social (oligarquía/resto de usuarios), podemos sugerir una red vertical al estilo de Putnam donde se vincule a agentes desiguales en relaciones asimétricas de jerarquía y dependencia (Putnam, 2000: 173). El objetivo de elaborar un estudio de redes puede ser muy fructífero si tenemos en cuenta que Ostrom y Ahn las interpretaban como un elemento clave del capital social con el que aproximarnos a los problemas de acción colectiva ${ }^{5}$. Por tal motivo, podríamos llegar a plantear que en las huertas de gestión municipal pudo existir una fuerte interdependencia entre el conjunto de los usuarios, por un lado, y la minoría oligárquica, por otro ${ }^{6}$. Proponemos, por tanto, una gestión compartida entre ambos, o lo que es lo mismo, un término medio entre la "democracia de los regantes" y el libre albedrio de las autoridades/elites municipales. Para aproximarnos a dicha interdependencia, seguiremos los notables trabajos de Garrido (2011 y 2012) sobre el complejo macro-sistema de irrigación de la Plana de Castelló (en la desembocadura del río Mijares) y la aplicación teórica de Ostrom en ellos. Para ello nos centraremos en dos de las cinco unidades de gestión que lo componen: las instituciones de riego de Castelló de la Plana y Vila-real, siendo la primera de ellas -según Glick (1988: XII-XIII)- un ejemplo paradigmático de huerta de gestión municipal.

De esta manera, para destacar el papel jugado por el conjunto de los usuarios en relación a las autoridades municipales de Vila-real y Castelló, utilizaremos un estudio comparativo con respecto al modelo autónomo. El objetivo será el de razonar que mecanismos de participación tenían los usuarios en la Plana para resolver aquellos mismos objetivos que conllevaban una asamblea de regantes en la Huerta de Valencia. Para llevar a cabo este ejercicio, seguiremos un esquema sencillo basado en los tres objetivos que según Glick (1988: 32-33) eran susceptibles de convocar tanto Juntas Generales como extraordinarias: 1) "llevar a cabo proyectos de construcción y financiación de obras que precisaban la atención inmediata de los comuneros" 2) "elegir a sus oficiales y funcionarios", y 3) "redactar y aprobar las Ordenanzas". Con ello trataremos de ver cómo, a diferencia de la

4. Garrido, S. (2011: 36) advierte que el intervencionismo monárquico hay que relativizarlo pues solo es verdaderamente significativo cuando las comunidades han de enfrentarse con el exterior.

5. Ostrom, E. y Ahn, T.K. (2003: 189-191). "Cuando los individuos confiables que están dispuestos a cooperar con otros constituyen sólo una pequeña minoría de la población total de la sociedad, una condición para que puedan sobrevivir, prosperar y expandirse es establecer una red [...]. Las redes [...] estimulan el avance de la norma de reciprocidad mediante la transmisión de información entre los individuos que son confiables y aquellos que no lo son".

6. Ostrom, E. (2000: 77). "Cuando muchos apropiadores dependen de un RUC [recursos de uso comunal] determinado como fuente de actividad económica, se ven afectados colectivamente en casi todo lo que hacen. Cada individuo debe tomar en cuenta las elecciones de los otros cuando evalúa sus elecciones personales. [...] Se encuentran atados en un entramado de interdependencia mientras sigan compartiendo un solo RUC”. 
Huerta de Valencia donde al parecer se utilizó un procedimiento más o menos homogéneo -la asamblea-, en la Plana los usuarios pudieron utilizar éste y otros cauces para participar en la gestión de las instituciones de riego, obteniendo así resultados muy similares a los del modelo autónomo, aunque sin desprenderse nunca del peso jugado por las autoridades municipales.

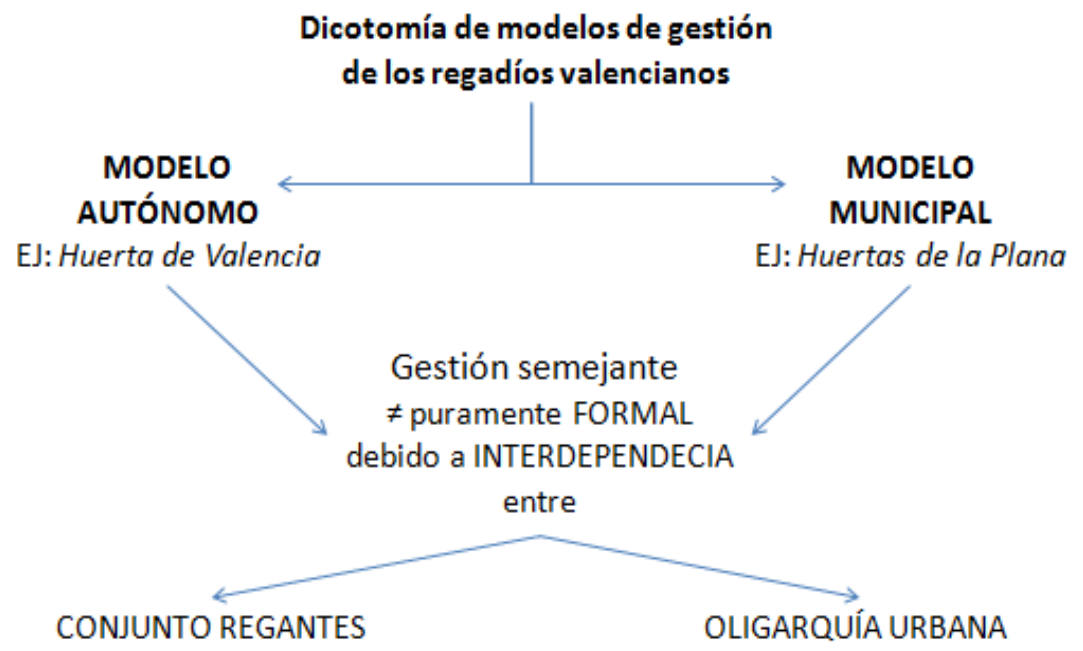

Fig. 2. Esquema propuesto sobre la dualidad de modelos de gestión de los regadíos valencianos. Elaboración propia.

\section{Proyectos de construcción y la búsqueda de financiación}

En su importante obra, Glick expone que en la Huerta de Valencia existía un tipo de asambleas donde se discutía sobre la financiación de las obras (Glick, 1988: 33). Son éstas, por tanto, unas decisiones colectivas de tipo extraordinario tomadas en un momento muy preciso. Este tipo de decisiones, como bien apuntó Garrido, no pueden encontrarse en la normativa ordinaria ${ }^{7}$. Por tal motivo, es necesario buscar entre los archivos municipales la manera en que el conjunto de los usuarios reaccionaba ante una necesidad puntual no contemplada en las ordenanzas. Así pues, expondremos varios casos relacionados con la búsqueda de financiación para la construcción y reparación de las acequias de la Plana. Estos ejemplos son prácticamente inéditos y nos servirán tanto para observar las características de estas asambleas en las instituciones de riego de la Plana, como para analizar su evolución a lo largo de la Época Moderna.

\subsection{Periodo foral}

Para ello, es importante citar en primer lugar el caso de los llamados: Diluvis d'aigües. Circunstancias en las que, como consecuencia del propio clima mediterráneo caracterizado por sus escasas pero concentradas precipitaciones-, se desbordaba tanto el río Mijares como otros barrancos cercanos, ocasionando terribles daños físicos y materiales. Para su estudio contamos con seis unidades archivísticas procedentes del

7. Garrido, S. (2011: 23). "en ninguna Ordenanza se fijan con detalle los criterios a utilizar para el reparto del agua durante las sequías [...], pero tales criterios existían". 
Archivo Municipal de Vila-real, de las cuales hemos estudiado las de $1581^{8}$ y $1605^{9}$ debido a su mayor riqueza de contenido.

Actualmente conocemos pocos detalles sobre estas dos inundaciones y sus efectos ${ }^{10}$, pero no obstante, lo verdaderamente interesante para este estudio es que nos permiten rastrear como se reaccionó colectivamente ante dichos problemas. Nos estamos refiriendo a situaciones extremas donde el Consell se veía completamente desbordado. Dicha corporación no era lo suficientemente capaz como para llevar a buen puerto la reconstrucción de una huerta destruida por las aguas. Era necesario pues, que los altos cargos municipales se reunieran en una asamblea multitudinaria con el conjunto de los terratenientes de la huerta vila-realense para "veure com se puga imposar cantitat corresponent per a pagar lo gran dany causat"11.

El análisis de estas dos asambleas extraordinarias nos servirá para dar respuesta a cuatro importantes cuestiones: 1) ¿cómo se convocaban?, 2) ¿dónde se celebraban? 3) ¿quién asistía a estas asambleas? y 4) ¿qué tipo de decisiones se tomaban en común?

Para conseguir que media huerta se reuniera en un mismo punto y que la convocatoria no

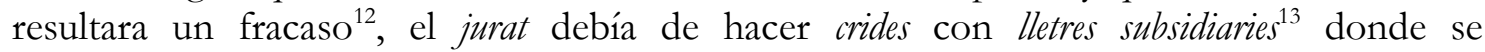
informaba del día, la hora y el lugar de la reunión. Estas cartas no solo eran enviadas a todos los terratenientes de Vila-real, sino que se amparaba en la pragmática de Sueca ${ }^{14}$, involucrando a los terratenientes vecinos de otras villas con posesiones en ésta.

El lugar elegido para celebrar dicha asamblea, nos puede recordar mucho al modelo autónomo, si en la Huerta de Valencia las Juntas se celebraban usualmente en edificios eclesiásticos, como el monasterio franciscano de la ciudad de Valencia o el monasterio de la Trinidad (Glick, 1988: 33), en Vila-real se utilizó espacios análogos. El lugar elegido en los dos casos fue la iglesia o "casa hospital dels benaventurats archàngel sant Miquel i Verge santa Llúcia" un lugar espacioso situado "fora los murs de la dita vila (...) en lo arraval de València" ${ }^{\prime \prime}$.

Por lo que se refiere a la tercera cuestión, hay que decir que todavía hoy sigue siendo muy difícil saber a qué se refieren los textos históricos cuando usan términos como terrateniente o labrador. No obstante, para éste ejemplo, queda claro que se refería al conjunto de usuarios que tenían derecho al agua. En el diluvio de 1581 se nos ofrece un censo de los terratenientes asistentes a la reunión. De este modo sin contar al justicia y a los

8. Archivo Municipal de Vila-real (AMVr.) Hacienda. Fiscalidad. 1204/1581. Proceso realizado para la implantación del impuesto denominado Dret nou, creado para remediar los daños causados por las inundaciones del Mijares en las azudes y acequias.

9. AMVr., Hacienda. Fiscalidad. 1209/1605. Administración de los derechos impuestos para la reparación de las acequias y azudes de Villarreal.

10. El cronista Benito Traver (1909: 143) describió que la avenida de 1581, "ocasionó á los vecinos de Villarreal grandes daños y perjuicios; no solamente los derrumbamientos de los molinos que á orillas del cauce del río se encontraban, sino que también por la falta de funcionar de estos molinos harineros", lo que provocó una carestía.

11. AMVr., Colecciones facticias, Cartas. 3653/1604.

12. Glick, T. (1988: 34). Para este autor "la falta de éxito" no se debía a la poca asistencia en si "sino más bien a la ausencia de aquellos cuyo interés y apoyo era necesario para que resultara un éxito cualquier proyecto importante".

13. AMVr., Hacienda. Fiscalidad. 1209/1605. Administración...

14 Sobre la pragmática de Sueca véase: Branchat, V. (1785: III, XLIV).

15. AMVr., Hacienda. Fiscalidad. 1209/1605. Administración... 
jurats -calificados como "administradors de les aigües i cequiers" ${ }^{16}$-, podemos afirmar que asistieron aproximadamente unos 256 usuarios, incluyendo también a aquellos terratenientes avecindados en poblaciones cercanas como Nules, Mascarell, Vilabella, Uxó, Artana, Eslida o Betxí.

La importancia de esta cifra recae en que si la comparamos con el "Llibre de sequiatge" de 1551, estudiado por Román (2000: 107-135), nos damos cuenta de que dichos terratenientes representaban en realidad cerca del 53\% del total de los usuarios de la huerta de Vila-real ${ }^{17}$. Así que con estas cifras creemos que siguiendo las palabras de Glick, para este caso terratinents significa todos los usuarios (Glick, 1988: 33), entendidos éstos como los propietarios (labren ellos mismos o no) que abonaban el impuesto de cequiatge.

El resultado de estas asambleas era claro, por una parte el Consell necesitaba organizar la cuantiosa mano de obra que debía llevar a cabo las reparaciones en el azud y las acequias. Mientras que por otra, precisaba también del esfuerzo económico de todos para aplicar un nuevo impuesto extraordinario necesario para hacer frente a los duros gastos. Este impuesto se pagaba a posteriori, ya que debido a la urgencia que se tenía en retornar a la normalidad, no podían esperar a recaudarlo. El Consistorio financiaba en primera instancia todos los gastos y una vez acabados y cuantificados se aplicaba una derrama comunitaria. Este Dret Nou, como se llamó comúnmente, era pagado en especie según zonas ${ }^{18}$.

Podríamos pensar pues, que los Consells -y en su defecto las oligarquías que los controlaban-, no gestionaban el espacio irrigado de forma totalmente ajena a las necesidades del conjunto de los usuarios. En momentos excepcionales, cuando veían desbordada su eficiente gestión ordinaria, contaban con la opinión común. Y con ello, evitaban posibles reproches surgidos contra medidas "duras" o impopulares ${ }^{19}$. De esta manera, sin ser impuestas, dichas medidas eran propuestas igualmente desde la corporación municipal, pero bajo la justificación de haber sido expuestas y debatidas entre todos los asistentes. Dichas asambleas de regantes podrían constituir a su vez un mecanismo de legitimación para aquellas medidas, que sin formar parte de la normativa ordinaria, requerían un especial esfuerzo comunal.

\subsection{Periodo borbónico}

Una vez visto cómo se efectuaba una asamblea extraordinaria en una huerta de gestión municipal durante los siglos XVI y XVII, es cuanto menos interesante preguntarnos si dichas juntas siguieron siempre el mismo modelo o si por el contrario sufrieron cambios a lo largo de los siglos. Una cuestión que trataremos de responder mediante la comparación de éstas con otras efectuadas durante 1786 en la localidad de Castelló de la Plana. La asamblea que trataremos a continuación es tan importante como desconocida hasta ahora, pues está inmersa en el contexto de la obra de un nuevo tramo de la acequia mayor con el

16. AMVr., Hacienda. Fiscalidad. 1205/1583. Cuentas de la administración del derecho de Dret nou e nou imposit para la reparación de acequias y azudes de Villarreal.

17. Nos parece interesante remarcar que entre los reunidos no se encuentran los terratenientes moriscos, que habitando pueblos vecinos, poseían cerca del 18,1\% de la huerta en 1551 . Y si estuvieron, no consta ninguno de los nombres arábigos localizados en el "llibre de cequaitge" de dicho año.

18. AMVr., Hacienda. Fiscalidad. 1209/1605. Administración... "un almut i mig de forment per cadascuna caffiçada azezat acolmat de totes les terres regadius del terme de la present vila arbolades $\mathrm{i}$ de les terres campes fins al sedeny que puja del molí de don Vicent Semís als Nangos. I de dit sedeny fins al cap de terme mig almut per cafficada de les terres que no estaran plantades".

19. Recordemos el tercer "Principio de diseño" de Ostrom (2000: 151-153), según el cual "la mayoría de los individuos afectados por las reglas operativas pueden participar en su modificación". 
que se trataba de acabar con los problemas que desde la Edad Media tenían los usuarios de esta huerta con los de Almassora, puesto que ambas instituciones compartían el azud y los primeros quilómetros de la acequia desde el siglo XIII ${ }^{20}$.

La primera diferencia es de tipo formal, puesto que no debemos olvidar que mientras que en el periodo foral la gestión de la asamblea correspondía al Consell, desde 1707, tras la Guerra de Sucesión, será el Ayuntamiento quien se encargue de ello. Este aspecto es importante por la siguiente razón: mientras que durante la época foral los Consistorios de la Plana convocaban las asambleas libremente cuando les eran necesarias, ahora, siendo súbditos de una nueva dinastía centralista, ésta localidad tendrá que pedir permiso a la Real Audiencia para que ésta le conceda "facultad y permiso [...] para celebrar [...] una o más juntas generales en la Casa Capitular presidiendo la justicia para tractarse con reflexión detenida los medios que aseguren oportunamente la tranquilidad y ventajas del Común" ${ }^{21}$.

Estos medios hacían referencia a la búsqueda de financiación, puesto que para conseguir que el monarca diese su aprobación a la obra era indispensable que éste no tuviera que hacerse cargo de los gastos, de manera que el Consistorio insistió en que los costes de la obra no afectarían a las arcas de la Corona, sino que sería el conjunto de los terratenientes de la huerta castellonense quienes "pagarían los gastos de la solicitud y el corte del cause nuevo para distribución de las aguas" 22. Bajo esta condición, la Real Audiencia dio "facultad para [realizar] las Juntas Generales [...]: las quales se celebran en el día de fiesta, convocándose en el antecedente por público pregón y la preside el alcalde mayor de la villa de Castellón" ${ }^{23}$.

Esta Junta General se efectuó el 7 de mayo de 1786 y contó con dos nuevas diferencias formales respecto a las de los siglos anteriores. Por un lado, la secularización del espacio asambleario, es decir, un abandono de los lugares religiosos en favor del Ayuntamiento y, por otro, el descenso experimentado en el nombre de asistentes, en torno a los cien. Una cifra, a nuestro entender, bastante modesta si recordamos que en la de 1581 participaron casi el triple de terratenientes ${ }^{24}$. Aún así, un análisis de los asistentes nos permite observar un aspecto que no ha cambiado, y es que sigue existiendo cierta diversidad social entre el conjunto de los asistentes. En ella podemos encontrar desde propietarios de tierras amortizadas, como los representantes de los conventos de Santa Bàrbera, Capuchinos, Santo Tomás o Santa Clara, hasta miembros de las familias más destacadas de la capital de la Plana -como los Mas, los Egual, los Giner, los Català o los Tirado ${ }^{25}$ - sin olvidarnos de otros labradores de familias menos adineradas.

Así pues, una vez reunidos, tras una breve exposición de los malestares que la población castellonense tenía contra sus vecinos, se aprobó la construcción de la nueva acequia. Pero esta no fue la única función de la Junta General y, al igual que lo aprobado en Vila-real doscientos años antes, se acordó la creación de una derrama comunal "de cantidad equitativa", pero, con la diferencia de estar expresada en moneda y no en especie. De este

20. García, V. (2013) ha editado en su colección de documentos sobre los derechos históricos de los pueblos de la Plana en materia de aguas, las concordias de 1275, 1290, 1297, 1338, 1344 y 1355, así como los pleitos de 1588 y 1635 entre Castelló y Almassora.

21. AMC., Aguas, caja núm 15, s/n. Certificación de acuerdo a la Real Audiencia sobre la construcción de un Nuevo cauce para la acequia mayor.

22. AMC., Aguas, caja núm 15, s/n. Certificación de acuerdo...

23. AMC., Aguas, caja núm 15, s/n. Certificación de acuerdo...

24. Bajo nuestro punto de vista este descenso podría deberse a que las causas que motivaron la asamblea de 1581 eran muchos más urgentes debido a la completa desolación ocasionada por las inundaciones.

25. Para saber más sobre la oligarquía castellonense véase: Gimeno (1998). 
modo, se abonó la derrama "a razón de una peseta por cada anegada de tierra huerta, y la de media peseta por cada de tierra olivar" ${ }^{26}$. Para recaudarla se nombró a cinco individuos y se les atribuyó a cada uno de ellos una o dos parroquias. Puede decirse que, por norma general, los usuarios pagaron lo establecido, pero que aún así, el 17 de marzo de 1787, el corregidor tuvo que elaborar un auto con el que hacer frente a la morosidad de una minoría de terratenientes. Después de innumerables prórrogas, y llegados al 1 de abril de 1788, el Ayuntamiento optó por amenazar a los morosos con el embargamiento y subasta pública de sus tierras, mientras contrataba los servicios del abogado Vicent Vilar para someter los hechos a la justicia ordinaria ${ }^{27}$.

Paralelamente a los problemas de financiación, cabe destacar la creación de una coordinadora de quince usuarios a la cual se le concedieron plenos poderes con el pretexto de agilitar el proceso de construcción, evitando así que la Junta General tuviera que ser convocada cada vez que se tuviera que tomar una decisión importante. Esta coordinadora nos es interesante por dos motivos. Primero porque en la documentación se hace referencia a la intención de que ésta sea compuesta por usuarios "de todas clases y estados", es decir, una composición bastante heterogénea: "uno de los individuos del Ayuntamiento; otro por el secular; otro por el clero regular; dos de la clase de cavalleros; dos de la de facultativos; seis de la de labradores; y dos por los gremios de oficios". Y segundo por el modo en que se efectuó la elección, puesto que "cada uno [de los asistentes] propuso los que le parecieron convenientes, y por más número de votos quedaron nombrados" ${ }^{28}$. Un procedimiento que, a nuestro parecer, queda bastante lejos de la imagen que se suele tener sobre los regadíos de gestión municipal y el predominio de la oligarquía urbana en la toma de decisiones.

\section{Elección de oficiales y funcionarios}

Utilizando el ejemplo de la acequia de Tormos (Valencia), Glick (1988: 32-33) recogió la convocatoria de asambleas anuales con el objetivo de elegir a los oficiales y funcionarios. En el caso de la Plana, a priori podríamos pensar que nunca existieron estas asambleas como tales y que por tanto el papel de los usuarios en este sentido fue poco importante en comparación con la Huerta de Valencia. No obstante, hay dos aspectos que pueden hacernos cambiar de opinión.

Por una parte, hay que decir que en el Castelló medieval, el nombramiento de los funcionarios del Consell se libraba anualmente mediante una subasta o licitación competitiva para ver quien conseguía el cargo por el menor costo (Glick, 1988: 39), aspecto común en la vecina Vila-real, como bien ha estudiado Román (2000: 97). Así pues, creemos razonable pensar que aunque la elección no se hiciera por consenso en una reunión multitudinaria, tampoco existió ninguna norma que limitase la participación en la subasta a unos usuarios determinados. Así que a efectos prácticos no había gran diferencia. La elección mediante subasta permitía que los nombramientos no fuesen impuestos libremente por los jurats, ya que al cargo podía acceder cualquier usuario, aunque eso sí, siempre y cuando tuviera posibilidades económicas para afrontar importantes gastos (Román, 2000: 97). Un aspecto común, sin duda, en la Huerta de Valencia, donde los cequiers -aunque fueran elegidos en asamblea- tenían que hacer frente a esta misma condición. Dicho esto, ha de advertirse que el nombramiento de estos cargos públicos no siempre fue igual a lo largo de los siglos. Hay

26. AMC., Aguas, caja núm 15, s/n. Certificación de acuerdo...

27. AMC., Aguas, caja núm 15, s/n. Certificación de acuerdo...

28. AMC., Aguas, caja núm 15, s/n. Certificación de acuerdo... 
que tener en cuenta los efectos producidos por la insaculación primero ${ }^{29}$ y la castellanización institucional después. Dos importantes cambios que, seguramente, modificaron las posibilidades de acceso al cargo de acequiero mayor. De producirse este cambio en favor de una oligarquía urbana ${ }^{30}$, que pudo ver en este cargo una forma más de promoción social ${ }^{31}$, habría que ponerlo en relación con el hecho de que en la Huerta de Valencia, las asambleas de regantes fueron disminuyendo sus convocatorias a lo largo de la Edad Moderna (Burriel, 1971: 216).

Un segundo aspecto a destacar es el hecho de que en la huerta de Castelló, cada partida o estructura organizativa menor, tenía a su cargo un probom. De este modo, independientemente de cómo fueran nombrados los acequieros de Castelló ${ }^{32}$, podemos decir que al menos en 1756, los prohoms -aunque en algunas partidas puntuales fueran designados "por la justicia y regimiento de esta villa" ${ }^{3}$-, eran elegidos directamente por los usuarios en la mayoría de los casos ${ }^{34}$. Este prohom tenía que ser un "labrador del mismo partido, experimentado, de buenas costumbres y nada necesitado" ${ }^{35}$, o lo que es lo mismo, un usuario con cierta reputación entre sus vecinos, cuyo principal cometido era el de "repartir el agua [...] con igualdad y equidad, atendiendo siempre a la mayor necesidad" 36 . Parece claro pues, que estos delegados no formaron parte de la oligarquía urbana $-\mathrm{O}$ al menos directamente-, pero como veremos a continuación, creemos que eran en realidad una clase de labradores acomodados que se encontraba a medio camino entre las élites y el resto de los usuarios. Para comprender esto analizaremos dos prohoms al azar.

Joseph Albiol, prohombre del Censal, en el Manifiesto de Bienes de $1751^{37}$ contaba con una casa de dos alturas en pleno centro de la ciudad junto con la mitad de una casa y corral para el ganado; tres fincas de regadío con un total de 55 hanegadas, 2 cuartones $^{38}$ y una alquería; 6 fincas en el secano con tres hanegadas y 3 cuartones cultivados al menos con algarrobales y olivos. Sus bienes estaban valorados en 3.461 libras, a las que habría que restar 1.837 libras que tenía en nueve deudas.

Miquel Navarro, prohombre de Rafalafena, era un ejemplo algo diferente, según el Manifiesto de Bienes de $1759^{39}$ solo tenía una casa de una altura en el centro urbano; cuatro fincas en el regadío con una alquería y 21 hanegadas y media; 3 fincas de viña y

29. Para el Castelló de principios del siglo XVIII el acequiero contaba con su propia bolsa de insaculación (Villamarín, 2014: 38). Una bolsa donde encontramos indistintamente ciudadanos, artistas o labradores (Villamarín, 2014: 32-33).

30. Desde el privilegio insaculador de 1627 en Castelló de la Plana se excluyó a los oficios mecánicos de esta bolsa (Arroyas, 1989: 52-88).

31. A lo largo del siglo XVIII es muy fácil localizar a miembros de las familias Tirado y Breva como acequieros mayores de Castelló, familias de gran reconcomiendo en esta ciudad, que acabarían por ostentar el título de hidalguía (Gimeno, 1998: 290).

32. El Consell y luego el Ayuntamiento de Castelló nombraba anualmente a tres acequieros, el cequier maior" y los de Coscollosa y Taxida.

33. Archivo Municipal de Castelló (AMC.), Aguas, caja 13, s/n. Capítulos y ordenanzas para el riego de la partida de Censal.

34. AMC., Aguas, caja 13, núm. 97. Capítulos y ordenanzas para el riego de la partida de Rafalafena "se nombra un prohombre cuya elección la hacen los mismos terratenientes".

35. AMC., Aguas, caja 13, núm. 95. Capítulos y ordenanzas para el riego de las partidas de Gumbau y Soterrani.

36. AMC., Aguas, caja 13, núm. 97. Capítulos y ordenanzas para el riego de la partida de Canal.

37. AMC., Manifiestos de Bienes, Parroquia de Santo Tomás, caja 12, s/n.

38. Seguramente el texto no se refiere a un cuartón de hanegada $(0,25$ hanegadas) sino a un cuartón de jovada (9 hanegadas).

39. AMC., Manifiestos de Bienes, Parroquia de Santo Tomás, caja 12, s/n. 
algarrobo en el secano con una extensión total de 7 hanegadas. En resumen, sus bienes eran mucho menores que el anterior (1.344 libras), pero por el contrario estaba mucho menos endeudado (una única deuda de 38 libras). Por lo que en realidad no se diferenciaba mucho del anterior en cuanto al valor neto (bienes menos deudas).

Podríamos decir pues, que estos prohoms eran labradores de oficio, cuyos bienes tendrían un valor neto de entre 1.000 y 2.000 libras $^{40}$. Propietarios por tanto, con alguna posibilidad de ocupar cargos públicos, que disponían de diversos lotes de tierra repartidos por todo el término municipal y con policultivo. Aunque, evidentemente salieron elegidos en las partidas donde más tierra tenían concentrada. Miquel Navarro -prohom de Rafalafena- tenía allí 18 hanegadas y un cuartón, mientras que Joseph Albiol -prohom de Censal- tenía 49 hanegadas y media. De este modo, aunque no eran miembros de las grandes familias ni poseían mayorazgos, creemos que podían gozar de una importante influencia en sus respectivas partidas, con el agravante de que a diferencia de la oligarquía éstos estaban más próximos al resto de los regantes. De esta manera, hemos podido observar como en una huerta de gestión municipal, el riego en cada estructura organizativa menor era coordinado por los propios usuarios mediante la elección interna de uno de ellos.

\section{Redacción y aprobación de las Ordenanzas}

El siguiente caso a exponer, alude a aquellas asambleas que según Glick (1988: 32) tenían como objetivo aprobar ordenanzas, aunque nosotros por extensión aplicaremos este criterio a la aprobación de cualquier acuerdo colectivo interno en el seno de las instituciones de riego de la Plana. Para analizar este tercer y último caso, realizaremos una diferenciación entre aquellas normas redactadas en época foral (principalmente al siglo XIV) y las de periodo borbónico (siglo XVIII).

De esta manera, por lo que se refiere a la Edad Media, cabe destacar que al contrario de lo ocurrido en las acequias de Benàger y Faitanar (València) durante $1435^{41}$, las ordenanzas de riego de Vila-real y Castelló ${ }^{42}$ no describen ni los procesos de redacción, ni los personajes participantes en su aprobación. Por lo tanto, de igual manera que para la Huerta de Valencia se han perdido los registros de cequiaje ${ }^{43}$, para la Plana no se han conservado las actas de aprobación de las ordenanzas forales. Así pues, no tenemos ninguna prueba factible que nos indique la convocatoria de asambleas de regantes con este fin durante el periodo foral.

No ocurrirá lo mismo en 1756, momento en el que "habiéndose reconocido por el libro del sequiero de esta villa lo diminuto y la poca formalidad de el arreglamento del riego de la huerta del término, de lo que nace el desgobierno que han tenido y tienen entre si los regantes" ${ }^{\prime 4}$ el corregidor de Castelló, Josep Bermudo, ordenó reelaborar las ordenanzas de riego de la villa al modo castellano ${ }^{45}$. Con esta orden, se produjo una importante paradoja.

40. Tengamos en cuenta que para poderse insacular como ciudadano tenían que demostrar en propiedad más de 1.000 libras en bienes (Gimeno, 1998: 168).

41. Glick, T. (1988: 32) Asamblea de 84 regantes realizada con tal fin en el claustro del Monasterio de San Francisco de Valencia. Este ejemplo fue el elegido por Ostrom (2000: 121) para iniciar el apartado sobre "las instituciones de irrigación de las huertas" en su prestigioso "Governing...".

42. Véase: Gil, V. (2002) y Revest, L. (1957)

43. Glick, T. (1988: 43). Aunque dicho autor argumenta que existieron.

44. AMC., Aguas, caja 13, núm. 99. Capítulos y ordenanzas para el riego de la partida de Zafra.

45. Suponemos que lo que las nuevas autoridades borbónicas pretendían en realidad era que se fijara por escrito todos aquellos cambios normativos que, efectuados durante toda Edad Moderna como resultado de la 
Mientras la nueva dinastía borbónica trataba de llevar a cabo una política centralista, el éxito de las instituciones de riego de la Plana se había debido precisamente a la ausencia de un agente externo en su gestión interna ${ }^{46}$. Así que, ante el auto de Bermudo, es interesante cuestionarse si una intromisión de la corona en la gestión de estos regadíos podría romper el status quo que durante siglos imperaba en estas instituciones comunales.

Evidentemente, esta circunstancia nos remite a "la teoría del estado", la cual trataba de dar respuesta a los problemas de acción colectiva mediante la intromisión de un agente exterior (la Corona en este caso). En contrapunto, Ostrom utiliza un razonamiento teórico para llegar a la conclusión de que, en realidad, no sería necesario acudir a un agente externo para resolver dichos problemas, a condición de que las reglas del juego también hayan sido diseñadas por los propios usuarios (Garrido, 2011: 15). Así pues, bajo nuestro punto de vista, el análisis de las ordenanzas borbónicas de 1756 nos permite observar que el éxito comunal no estaba ligado necesariamente a la intervención de un agente exterior. No solo por el hecho de que apenas se aportó grandes novedades al contenido de las mismas ${ }^{47}$, sino porque a diferencia de la documentación foral, ésta nos ofrece por primera vez una evidencia de cómo pudieron ser los procesos de aprobación de las normas colectivas en la Plana. Un proceso donde el conjunto de los usuarios participó de forma más que activa.

Para entender correctamente su implicación, cabe destacar que con estas ordenanzas se llevó a cabo una descentralización de la normativa municipal. En lugar de establecer unas ordenanzas de carácter general que afectaran al conjunto del territorio municipal -al estilo foral-, se redactaron ocho reglamentos distintos atendiendo a las condiciones específicas de cada partida o agrupación de partidas ${ }^{48}$. Esta articulación social, la entendemos según el octavo principio de Ostrom llamado: estructura anidada o incrustada ${ }^{49}$. Garrido propone la existencia de al menos tres niveles de organización anidada para las comunidades de regantes del este de España. El primero se evidenciaba cuando diferentes instituciones vecinas se unían para defender sus intereses comunes frente a terceros, el segundo lo constituían las propias comunidades de regantes y el tercero de ellos hacía referencia a las derivaciones principales de la acequia mayor (Garrido, 2011, 37). Nosotros damos por muy válida esta clasificación, pero para este caso concreto interpretaremos el tercer nivel en el sentido de partida rural, no entendiéndola solo como un espacio geográfico sino también como un espacio social.

Recordemos que, tal i como ya observaron Bernat i Badenes (1994), la población de Castelló se incrementó de forma muy destacada durante el siglo XVIII ${ }^{50}$. El setecientos produjo en esta ciudad un importante crecimiento demográfico que pudo derivar en un aumento muy significativo del número de regantes. Así pues, creemos que unido al

propia evolución de las instituciones de riego y la sociedad que daba uso de ellas, habían dejado a las antiguas ordenanzas medievales desfasadas en la práctica.

46. Juan de Aragón reconoció en 1446 la competencia de los Consells de Vila-real y Castelló en imposiciones comunales por acequias y cequiaje, impidiendo a los oficiales reales que perturbaran al municipio en la práctica de dicha facultad. Documentos transcritos en: García, V. (1994: 187-189).

47. Desde el primer momento estas ordenanzas dejan claro que no hay intención de realizar un cambio súbito, pues en las instrucciones del auto se expresa claramente que se hagan "teniendo presente el método antiguo de regar, añadiendo o quitando lo que tuvieren por conveniente para el mayor gobierno del riego de su partida sin perjuicio de las demás”. A.M.C., Aguas, caja 13, núm. 99. Capítulos y ordenanzas para el riego de la partida de Zafra.

48. AMC, Aguas, caja 13.

49. Según se use la traducción de Garrido (2011) o la versión mexicana de “Goberning...” (2000).

50. En el vecindario de Campoflorido (1712-1713) Castelló contaba con 1.072 vecinos, mientras que, ochenta años después, el Diario de Valencia (1793) contabilizó 2.950 y Cabanilles (1975) 3.400. 
crecimiento lento pero imparable de las huertas a lo largo de los siglos (Garrido, 2012a), se produjo un proceso de articulación social más complejo, consolidándose de este modo unas redes personales que influenciarían y mucho en la gestión diaria de la huerta. De este modo, en Castelló existían subescalas organizativas que creemos fueron básicas para el éxito de este sistema de irrigación, pues facilitaban la participación de los usuarios. Como recoge Garrido (2011: 38) de Ostrom "el hecho de que las decisiones pudieran tomarse a distintos niveles permitía una mejor adaptación al medio. Y también permitía que la supervisión del conjunto del sistema pudiera ser ejercida de manera mucho más económica y efectiva".

Expuesta esta idea, podemos abordar la participación directa de los usuarios en la aprobación de las normas, una participación que se llevó a cabo mediante un proceso escalonado de asambleas en cada partida. De esta manera, el proceso se inicia con la orden de que "cada común tanda y partida celebre junta general de todos los regantes de ellas citados tras público pregón", esta primera asamblea -realizada por cada partida durante el mes de febrero de 1756- se materializó en "las salas de la sala capitular de esta villa", con la presencia del prohombre de la partida, el alcalde, un escribano y una media de seis "vecinos de esta villa y terratinientes y regantes". Su cometido era el de nombrar "quatro electos de los que se contemplan más hábiles y de más satisfacción entre sus mismos regantes para que éstos, juntamente con los oficiales, prohombres y cequiero, vayan formando y formen ordenanzas" ${ }^{51}$.

Estos electos podrían vincularse a lo que Glick denominó “autoridades delegadas”. Según él, en la huerta de Valencia estos individuos formaban una especie de Junta de Gobierno, y eran elegidos siguiendo diversos criterios, estado representado, en algunas ocasiones, por intereses de clase además de geográficos. Para dicho autor, el status de estos representantes y sus funciones reales no eran fáciles de definir en los documentos, aunque, al parecer, unas veces podían actuar como portavoces de un grupo particular dentro de la comunidad, y otras como representante de la totalidad de la comunidad (Glick, 1988: 35).

Para el caso de la Plana de Castelló, el perfil social de estos electos, tal y como podremos ver en el estudio de dos casos al azar, fue bastante heterogéneo, aunque sin desprenderse de los parámetros que hemos establecido sobre los prohoms.

Así pues, el labrador Agustín Molins, electo de Coscollosa, tenía ${ }^{52}$, una casa en la parroquia de santo Tomás, así como 6 fincas con un total de 16 hanegadas y medio cuartón (de ellas 10 hanegadas en Coscollosa), repartidas por todo el término y cultivadas con algarrobos y olivos. El valor de sus bienes era de 930 libras y 10 sueldos, con cuatro deudas que ascendían a 260 libras y 15 sueldos, es decir, un valor neto aproximado de 670 libras. Cifra algo menor a la de los prohoms estudiados, no llegando a las 1.000 necesarias para alcanzar un cargo público como aquellos.

Un caso totalmente opuesto a la par que significativo era el de don Pedro Mas ${ }^{53}$, quien en $1757^{54}$ poseía: tres casas, un corral y el molino harinero de Gumbau ${ }^{55}$. Por otro lado tenía

51. AMC., Aguas, caja 13, núm. 99. Capítulos y ordenanzas para el riego de la partida de Zafra.

52. AMC., Manifiestos de Bienes, Parroquia de Santo Tomás, caja 12, s/n.

53. Sobre la familia Mas de Castelló véase: Gimeno, M. J. (1998).

54. AMC., Manifiestos de Bienes, Parroquia de Santo Tomás, caja 12, s/n.

55. Paradójicamente, esta partida donde fue electo no es donde se encontraba su molino (aunque si tenía 68 hanegadas). Desgraciadamente en las ordenanzas de Gumbao no consta el nombre de sus electos así que no sabemos cómo defendió allí sus intereses molineros. 
dos alquerías en la huerta y doce fincas con un total de 127 hanegadas de algarrobales y viña valoradas en 17.290 libras, a las que habría que sumar 1.222 libras y 16 sueldos en once censos, además de doce deudas que ascendían a 2.952 libras. Su valor neto era por tanto de 11.560 libras y 16 sueldos, una diferencia más que evidente con el anterior que muestra la heterogeneidad de los usuarios.

Una vez elegidos, los electos de cada partida se reunían "todas las tardes de los domingos y fiestas en la casa que tengan por conveniente, de modo que estén arregladas dichas ordenanzas dentro el término de dos meses contados". Transcurridos los dos meses (abril de 1756), se reunieron de nuevo en presencia de un escribano a quien le dictaron unas ordenanzas basadas en la costumbre, pero dotadas como hemos dicho de la especificidad de cada partida. Esta participación directa de los usuarios liga con el séptimo principio de diseño de Ostrom (2000: 101), según el cual los usuarios disfrutaban de un mínimo reconocimiento del derecho a autoorganizarse. Sobre este principio, Garrido (2011: 36) ya apuntó que tal vez no era un mito el pensar que los labradores gestionaran estos espacios agrarios puesto que resultaba difícil suponer que los propietarios establecieran las reglas del juego sin tener en cuenta las prácticas cotidianas de los arrendatarios que realmente cultivaban sus fincas.

Éste es un proceso, por lo tanto, inverso al recogido por Calatayud y Garrido (2012: 109) para el caso de la Acequia Real del Júcar en 1844. Allí la iniciativa correspondió al jefe político, quien presentó un borrador de ordenanzas y, a continuación, reunió una comisión formada por representantes de los regantes para discutir el texto. En el caso de la Plana, al parecer, las riendas del proceso las condujeron los usuarios y la intervención municipal pareció limitarse a la presencia del alcalde, los acequieros $^{56}$ y los prohombres $^{57}$ en la primera reunión. No obstante, y aunque son una minoría, no debemos olvidar que entre todos los electos hay miembros de las familias Mas y Tirado, quienes durante el siglo XVIII ocuparon cargos municipales con gran asiduidad. De esta manera, aunque en el momento de redactar las ordenanzas de 1756 no actuaron en nombre del municipio, la oligarquía urbana castellonense podía participar en las decisiones como un usuario más en defensa de sus intereses.

Evidentemente, no existió ni una "democracia de los regantes" ni tampoco un predominio oligárquico a la hora de tomar las decisiones colectivas. En este regadío de gestión municipal, la oligarquía -instalada frecuentemente en los cargos municipales-, ni aprobó la normativa por sí sola, ni se quedó pasiva a la espera de lo que se decidiera desde abajo. Si unimos al Corregidor en la ecuación, podemos decir que las tres partes (Corona, oligarquía urbana y el resto de los usuarios) participaron de alguna manera en el proceso de la aprobación de estas ocho ordenanzas. Aunque lo más importante es destacar como los usuarios tenían una importancia más que destacada en todo ello.

\section{Conclusiones}

La existencia de asambleas de regantes no estaba reñida con el modelo de gestión municipal. Éstas podían convocarse y cuando se celebraban contaban con numerosos símiles formales a imagen de las asambleas extraordinarias del modelo autónomo, así como

56. Recordemos que Coscollosa y Taxida tienen acequieros propios.

57. De los cuales solo 3 de los 13 vigentes en aquel momento habían sido elegidos directamente por el Ayuntamiento, mientras que el resto lo habían sido por a los usuarios. 
peculiaridades propias derivadas de los diferentes contextos político-sociales y los objetivos a tratar.

Los diferentes objetivos que motivaban la convocatoria de asambleas en la Plana no siempre coincidían con los de Valencia. Podían existir, por tanto, otros procedimientos con los que obtener resultados muy semejantes, sin ser por ello excluyentes para el conjunto de los usuarios.

El uso de procedimientos diferentes, no implicó necesariamente que las autoridades municipales u oligarquías urbanas pudiesen tomar decisiones al margen del conjunto de los usuarios. Así que, en realidad, creemos que la exitosa gestión interna de las huertas de la Plana de Castelló implicó la participación de ambos grupos (la oligarquía y el resto de usuarios), puesto que entre ellos existió una fuerte interdependencia. No son, por tanto, dos clases necesariamente opuestas.

El conjunto de los usuarios, además -tal y como hemos tratado de demostrar con el análisis de los prohombres y los electos- no constituyeron un grupo homogéneo, sino que entre ellos cabe destacar la influencia de labradores acomodados que mediaban directamente con las autoridades municipales. Por tal motivo, es necesario que en el futuro se intente dar importancia al estudio detenido de elementos como el anidamiento institucional y las redes sociales, puesto que nos permitirán comprender la enorme complejidad social oculta en estos regadíos.

\section{Referencias}

Bernat, J.S. y Badenes, M.A. (1994): Crecimiento de la población valenciana. Análisis y presentación de los censos demográficos (1609-1857). València, Alfons el Magnànim.

Branchat, V. (1785): Tratado de los derechos y regalias que corresponden al Real Patrimonio en el Reyno de Valencia y de la jurisdicción del Intendente como subrogado en lugar del Antiguo Bayle General. Valencia, Imprenta de Joseph y Thomas de Ortega.

Burriel, E. (1971): La buerta de Valencia. Zona sur, València, Alfons el Magnànim.

Cavanilles, J. (1795): Observaciones sobre la Historia natural, geogräfica, agricultura, población y frutos del Reyno de Valencia, Madrid, Imprenta Real.

Calatayud, S. y Garrido, S. (2012): Negociación de normas e intervención estatal en la gestión del regadío: la acequia real del Júcar a mediados del siglo XIX, Hispania. Revista Española de Historia, 240:95-118.

Furió, A. (1982): Camperols Al País Valencià: Sueca, una comunitat rural a la tardor de la edat mitjana, Valencia, Institució Alfons el Magnánim.

García, V. (1994): Derechos históricos de los pueblos de la Plana a las aguas del río Mijares, Castelló de la Plana, Diputació de Castelló. 
Garrido, S. (2011): Las instituciones de riego en la España del este. Una reflexión a la luz de la obra de Elinor Ostrom, Historia Agraria, 53:13-42.

Garrido, S. (2012a): Ampliación del regadío, regulación institucional y sostenibilidad en las huertas tradicionales de la España mediterranea, Investigaciones de Historia Económica, 8:13-42.

Garrido, S. (2012b): Aprendiendo a regar imperios. Ingenieros, España y la India británica, Historia Social, 73:41-58.

Gil, V. (2002): Ordenances municipals de Vila-real: (segles XIV-XVIII), València, Universitat de València.

Gimeno, M.J. (1990): La Oligarquía urbana de Castelló en el siglo XVIII, Castelló de la Plana, Ajuntament de Castelló.

Gimeno, M.J. (1998): Patrimonio, parentesco y poder. Castelló (XVI-XIX), Castelló de la Plana, Diputació de Castelló.

Guinot, R. (2007): El gobierno de las aguas en las huertas medievales mediterráneas: los casos de Valencia y Murcia, en G. Del Ser y I. Martín, Ed., Espacios de poder y formas sociales en la Edad Media, Salamanca, Ediciones Universidad de Salamanca.

Glick, T.F. (1988): Regadío y sociedad en la Valencia Medieval, València, Del cenia al segura.

Jaubert de Passa, F. (1991): Canales de riego de Cataluña y Reino de Valencia, leyes y costumbres que los rigen: reglamentos y ordenanzas de sus principales acequias, (reedición preparada por J. Romero y J. Mateu), Madrid, Universitat de València-MAPA.

Ostrom, E. (2000): El gobierno de los bienes comunes. La evolución de las instituciones de acción colectiva, México, FCE.

Ostrom, E. y Ahm, T.K. (2003): Una perspectiva del capital social desde las ciencias socials: capital social y acción colectiva, Revista mexicana de sociología, 65-1:155-233.

Peris, T. (1992): Regadio, producción y poder en la Ribera del Xúquer. La Acequia Real de Alzira, 1258-1847, Valencia, C.O.P.U.T.-Confederación Hidrográfica del Júcar.

Peris, T. (1997): La conflictividad hidráulica en el País Valenciano entre los siglos XII y XVIII, Áreas: revista internacional de ciencias sociales, 17:43-60.

Peris, T. (2003): Problemas agrícolas y gestión hidráulica en la Huerta de Valencia, en M. Drain, Ed., Politiques de l'eau en milieu méditerranéen. Le cas de la péninsule Ibérique, Madrid, Casa de Velázquez, pp. 129-150.

Peris, T. (2014): El ejercicio de la autonomía local en las acequias de la huerta de Valencia: la olvidada imbricación municipal (siglos XIII-XIX), DT-SEHA, 14-04.

Putnam, R.D. (2000): Bowling Alone: The Collapse and Revival of American Community, New York, Simon and Shuster. 
Rabassa, C. (1999): La extensió del regadiu de Castelló durant la baixa edat mitjana, Sociedad Castellonense de Cultura, 75: 617-649.

Revest, L. (1957): Llibre de ordinacions de la Vila de Castelló de la Plana, Castelló de la Plana, Societat Castellonenca de Cultura.

Román, I. (2000): El regadio de Vila-real durante los siglos XIII-XV: origenes, administración y conflictos, Vila-real, Ajuntament de Vila-real.

Traver, B. (1909): Historia de Villarreal, Vila-real, Botella.

Villamarín, S. (2014): Castellón de la Plana 1700-1710. Último consistorio foral, Guerra de Sucesión y Nueva Planta, València, PUV. 